\title{
Reducing the risk of surgical site infection using a multidisciplinary approach: an integrative review
}

\author{
This article was published in the following Dove Press journal: \\ Journal of Multidisciplinary Healthcare \\ 13 October 2015 \\ Number of times this article has been viewed
}

\section{Brigid M Gillespie' \\ Evelyn Kang' \\ Shelley Roberts' \\ Frances $\operatorname{Lin}^{1,2}$ \\ Nicola Morley ${ }^{3}$ \\ Tracey Finigan ${ }^{3}$ \\ Allison Homer ${ }^{3}$ \\ Wendy Chaboyer'}

'National Health and Medical Research Council Research Centre for Clinical Excellence in Nursing Interventions (NCREN) and Centre for Healthcare Practice Innovation (HPI), Menzies Health Institute, ${ }^{2}$ School of Nursing and Midwifery, Griffith University, ${ }^{3}$ Surgical and Procedural Services, Gold Coast University Hospital, Gold Coast, QLD, Australia
Correspondence: Brigid M Gillespie National Health and Medical Research Council Research Centre for Clinical Excellence in Nursing Interventions (NCREN) and Centre for Healthcare Practice Innovation (HPI), Menzies Health Institute, Griffith University, Academic I, G0I Bldg_Rm 2.04, Parklands Drive, Southport, QLD 4222, Australia Tel +6I 755529718

Email b.gillespie@griffith.edu.au
Purpose: To identify and describe the strategies and processes used by multidisciplinary teams of health care professionals to reduce surgical site infections (SSIs).

Materials and methods: An integrative review of the research literature was undertaken. Searches were conducted in April 2015. Following review of the included studies, data were abstracted using summary tables and the methodological quality of each study assessed using the Standards for Quality Improvement Reporting Excellence guidelines by two reviewers. Discrepancies were dealt with through consensus. Inductive content analysis was used to identify and describe the strategies/processes used by multidisciplinary health care teams to prevent SSI.

Results and discussion: In total, 13 studies met the inclusion criteria. Of these, 12 studies used quantitative methods, while a single study used qualitative interviews. The majority of the studies were conducted in North America. All quantitative studies evaluated multifaceted quality-improvement interventions aimed at preventing SSI in patients undergoing surgery. Across the 13 studies reviewed, the following multidisciplinary team-based approaches were enacted: using a bundled approach, sharing responsibility, and, adhering to best practice. The majority of studies described team collaborations that were circumscribed by role. None of the reviewed studies used strategies that included the input of allied health professionals or patient participation in SSI prevention.

Conclusion: Patient-centered interventions aimed at increasing patient participation in SSI prevention and evaluating the contributions of allied health professionals in team-based SSI prevention requires future research.

Keywords: health care team, interprofessional, multidisciplinary, surgical wound, wound infection

\section{Introduction}

Despite remarkable advances in the use of surgical techniques and prophylactic antibiotics and environmental/ergonomic improvements in the operating room, surgical site infections (SSIs) remain a significant cause of patient morbidity and mortality, ${ }^{1,2}$ and are the third-most common source of hospital-acquired infection. ${ }^{3}$ Of concern is that SSIs occur in up to $30 \%$ of all surgical procedures, and yet most are preventable. ${ }^{4-6}$ The economic impacts on the health care system are substantial, including increased hospital length of stay and escalating hospital costs, rising from twofold to fivefold. . $^{3,7}$ These human and economic effects are compounded by overstretched health care systems, suboptimal integration in clinical processes, and fragmented approaches used by health professionals in wound-care management. ${ }^{8}$ Necessarily, there is a growing emphasis on the prevention of SSI. As part of this imperative, international guidelines 
and standards have more recently added recommendations advocating the use of a team-based approach in the prevention of SSI. ${ }^{3,7,9-11}$ However, there has been limited discussion of the processes and strategies used by health care teams as a collective in the prevention of SSI.

Leading international organizations, such as the World Health Organization, acknowledge that collaborative practice is essential for achieving a concerted approach to providing care that is appropriate to meet the needs of patients, thus optimizing individual health outcomes and overall service delivery of health care. ${ }^{8}$ Regardless of the context in which collaborative practice is implemented, research suggests that a team-based approach to health care delivery maximizes the strengths and skills of members of the health care team. ${ }^{12,13}$ Consequently, this increases the efficiency of the health service through reduction of service duplication, more frequent/expedient referral patterns, and greater continuity and coordination of care. ${ }^{8}$ As SSIs are a key indicator of quality care, ${ }^{5,14}$ implementing strategies that promote team-based approaches in their prevention is important.

\section{Team-based care}

In health care, teams take various form, eg, home care, surgical, acute care, or office-based teams, teams limited to one clinician and patient, and geographically disparate teams caring for ambulatory patients. ${ }^{15,16}$ Teams in health care can therefore be large or small, centralized or dispersed, virtual or face-to-face, while tasks can be focused and brief or broad and lengthy. ${ }^{16}$ This extreme heterogeneity in tasks/ roles, patient populations, and settings makes it difficult to define the most appropriate structure/model for optimal team-based health care that reflects the model of care in a particular setting. Fundamental to the success of any model of team-based care is the skill, reliability, and expertise of the individual members that comprise the team.

Team-based models of care have been conceptualized on a spectrum running from parallel practice, in which clinicians mostly work separately, to integrative care, in which the interdisciplinary approach is nonhierarchical and consensus-building, with many variations along the way. ${ }^{15,16}$ Key descriptors used to define health care teams include "interprofessional", "multiprofessional", "interdisciplinary", "multidisciplinary", and more recently "transdisciplinary". ${ }^{16-18}$ The prefix "inter" means between/among, and suggests that team members work interdependently to combine their knowledge in order to achieve a common goal that results in more than the sum of its parts. The prefix "multi" means many, and refers to team members from different disciplines working in parallel to treat the patient, but whose roles/ tasks do not necessarily overlap. The prefix "trans" means across or beyond; transdisciplinary collaboration refers to the inclusion of stakeholders that transcends disciplinary boundaries through role expansion. ${ }^{19}$ The findings of a recent integrative review concluded that the term most commonly used in the literature to describe the model of collaboration used by health care teams was "multidisciplinary" ${ }^{17}$ For the purposes of consistency, the term "multidisciplinary" will be used throughout this paper. However, irrespective of the terminology used, the model of collaboration used should be guided by the patient's needs, the particular health care setting, and the availability of staff and resources.

\section{Materials and methods}

The aim of this integrative review was to identify and describe the strategies and/or processes used by multidisciplinary teams of health care professionals to reduce SSIs. The conduct of this review was guided by the framework developed by Whittemore and Knafl. ${ }^{20}$ An integrative review allows the simultaneous synthesis of qualitative and quantitative research data to enable a complete understanding of the topic area under consideration. ${ }^{20}$ Consistent with this method of review, the five stages in the review process were problem identification, literature search, data evaluation, data integration, and presentation of results. ${ }^{20}$ In the context of multidisciplinary collaboration, this method of integration allowed us to examine and appraise research that has used diverse methodologies.

\section{Search methods}

An exhaustive search of the literature was conducted using the CINAHL (Cumulative Index to Nursing and Allied Health Literature), PubMed, Medline, ProQuest, and Cochrane Library databases. Search terms included a combination of keywords and MeSH (Medical Subject Headings) terms: "surgical site infection", "multidisciplinary", "interdisciplinary", "wound healing", "prevention", "postoperative wounds", "surgical wounds", "nutrition". MeSH terms were altered slightly where appropriate. Searches were also conducted on Google Scholar (forward citation searching) and reference lists of the included journal articles.

Our inclusion/exclusion parameters were based on the concepts studied, target population, health care issue, and sampling frame. ${ }^{20}$ The following inclusion criteria were applied. First, the sample had to involve health care teams comprised of nurses and/or physicians and/or allied health professionals practicing in acute care hospital settings. 
Second, studies had to focus on the implementation of processes and/or strategies intended to minimize the risk of SSI. Studies focusing only on the strategies or processes used by one particular discipline (ie, physicians) to reduce SSI were deemed ineligible, because the strategy was likely used in isolation without the input of other members of the multidisciplinary team. Third, only empirical, full-text articles written in English were considered. Finally, we included articles published from 1988 to 2015 due to the technological advances that have revolutionized wound-care practice over the last 30 years.

The following exclusion criteria were established: studies on chronic or acute wounds instead of postoperative acute wounds; studies that focused solely on the use of clinical interventions aimed at minimizing SSI (ie, antibiotic prophylaxis, shaving or clipping of patient's hair, hand washing), rather than on the collaboration among team members; research presented in the format of a thesis, book chapter, commentary, or discussion; and literature reviews.

\section{Data extraction and synthesis}

Specific information relevant to our research objectives was extracted. A second author independently screened all titles and abstracts for relevance based on the inclusion and exclusion criteria. The remaining papers were screened for suitability for inclusion by two authors, and a third author was available to adjudicate (although this was not necessary). In total, 13 papers met the inclusion criteria for this review.

\section{Appraisal of methodological quality}

As part of an integrative review methodology, quality scores are often used to aid data abstraction and synthesis. ${ }^{20}$ In this review, we critically appraised the methodological quality of research papers using the SQUIRE (Standards for QUality Improvement Reporting Excellence) guidelines, ${ }^{21}$ as the majority of articles reviewed were quality-improvements projects. These guidelines were used to appraise the quality of quantitative and qualitative studies included in this review, as the SQUIRE criteria comprehensively covered all aspects of the research, from the title, abstract, and study methods through to funding sources. Within the guidelines, there are 19 items with specific descriptors for each aspect of the study. Two authors used the SQUIRE guidelines to examine independently each article in detail (Table 1), and a third author was available to adjudicate. Scores for each criterion are either 0 ("no"), 1 ("partial"), or 2 ("yes"), or "not applicable". In this review, overall scores were calculated as a percentage based on the proportion of items applicable to each study. The proportion of interrater agreement was measured using the intraclass correlation coefficient, and a coefficient of $>0.70$ was considered acceptable. ${ }^{22}$

\section{Results Search outcome}

The initial search resulted in 559 articles and ten duplicates, and irrelevant articles were excluded. The titles and abstracts of 48 articles were retrieved and read. Articles were selected based on review of the abstracts against the inclusion and exclusion criteria. Full texts were retrieved when there was insufficient information in the abstract. Of the 48 articles screened, 13 met the inclusion criteria. Thirty-five articles were excluded for the following reasons: articles focused on chronic wounds rather than on acute surgical wounds $(n=20)$, and articles that did not discuss collaboration among multidisciplinary teams $(n=15)$. Figure 1 displays the search strategy and details the number of publications identified. The 13 articles included were from 2004 to 2015, with a predominance of the studies conducted in the US $(n=11)$, and the other two studies were from the Netherlands. Six of the articles reviewed were quality-improvement studies, six were quantitative studies, and one a qualitative study. A summary of the included articles describing the multidisciplinary approach in reducing SSI is presented in Tables 1 and 2 .

Across the 13 studies, multidisciplinary teams were comprised of nursing and medical department managers, nurse educators, nurses from the operative room or acute surgical units, physicians practicing in anesthesia, surgery, or infectious diseases, pharmacists, patients, and patient care technicians. Team composition varied, depending on the activities and location(s) of the health professionals involved. For instance, four studies ${ }^{23-26}$ focused on SSI-prevention strategies used exclusively by perioperative teams during surgery.

Six quantitative studies used a pretest-posttest design to evaluate the implementation of interventions, with sample sizes ranging from 197 to $35,543 .{ }^{24,25,27-29}$ One quantitative study with 602 participants used a cross-sectional survey to identify the problems that were associated with SSI before implementing intervention. ${ }^{28}$ In one qualitative study, a total of 18 health care professionals from a large tertiary center were interviewed using semistructured interviews. ${ }^{30}$

\section{Interventions}

Three team-based preventive strategies and/or processes were thematically identified through data synthesis: 1) using a bundled approach, 2) sharing responsibility, and 3 ) adhering to best practice. The majority of the 
Table I Characteristics of quality-improvement and quantitative studies

\begin{tabular}{|c|c|c|c|}
\hline Study, location & Design and sampling & Aim & Measures/interventions \\
\hline $\begin{array}{l}\text { Ballard et } \mathrm{al}^{27} \\
\text { USA }\end{array}$ & $\begin{array}{l}\text { - Pretest-posttest study } \\
\text { using retrospective } \\
\text { chart audit } \\
\text { - Single tertiary care } \\
\text { facility } n=394 \text { patient } \\
\text { charts total }\end{array}$ & $\begin{array}{l}\text { Evaluate infection rates in } \\
\text { pediatric patients having } \\
\text { spinal surgery before and } \\
\text { after implementation of a } \\
\text { multidisciplinary initiative } \\
\text { (Spinal Fusion Infection } \\
\text { Task Force) }\end{array}$ & $\begin{array}{l}\text { - Preoperative initiative: } \\
\checkmark \text { Hibiclens wash } \\
\checkmark \text { Apply } 2 \% \text { chlorhexidine to surgical site } \\
\checkmark \text { MRSA nasal swab } \\
\checkmark \text { Warming blanket } \\
\checkmark \text { Prophylactic antibiotics } \\
\text { - Intraoperative initiatives: } \\
\checkmark \text { Gowning/gloving for line placement } \\
\checkmark \text { Preincision antibiotics } \\
\checkmark \text { Antibiotic redosing } \\
\checkmark \text { Limit personnel in operating room } \\
\checkmark \text { Warming blankets } \\
\checkmark \text { Ensure availability of sterile instruments and devices } \\
\text { before surgery } \\
\checkmark \text { Postoperative initiatives: } \\
\checkmark \text { Discontinue antibiotics } 24 \text { hours postoperatively } \\
\checkmark \text { Remove drain prior to } 48 \text { hours postoperatively } \\
\checkmark \text { Initiate aggressive pulmonary therapy } \\
\checkmark \text { Reinforce/change dressings } 24 \text { hours postoperatively } \\
\checkmark \text { and remove } 4 \text {-5 or I0 days postoperatively } \\
\checkmark \text { Protect incision from moisture }\end{array}$ \\
\hline $\begin{array}{l}\text { Wick et } \mathrm{al}^{28} \\
\text { USA }\end{array}$ & $\begin{array}{l}\text { - Pretest-posttest study } \\
\text { using retrospective } \\
\text { chart audit } \\
\text { - Single hospital site } \\
\text { - } \mathrm{n}=278 \text { patients included } \\
\text { in preintervention } \\
\text { period } \\
\text { - } \mathrm{n}=324 \text { patients included } \\
\text { in postintervention } \\
\text { period }\end{array}$ & $\begin{array}{l}\text { Describe the relationship } \\
\text { between implementation of a } \\
\text { surgery-based comprehensive } \\
\text { unit-based safety program } \\
\text { (CUSP) and postoperative } \\
\text { SSI rates }\end{array}$ & $\begin{array}{l}\text { - Unit-based Safety Program multidisciplinary team } \\
\text { attended safety training, discussed concerns about SSI, } \\
\text { and implemented QI initiatives to improve teamwork in } \\
\text { their units } \\
\text { - Interventions included: } \\
\checkmark \text { Standardization of skin preparation } \\
\checkmark \text { Preoperative chlorhexidine wash cloths } \\
\checkmark \text { Selective elimination of mechanical bowel preparation } \\
\checkmark \text { Warming of patients in preanesthesia area } \\
\checkmark \text { Adoption of enhanced sterile techniques } \\
\checkmark \text { Addressing lapses in prophylactic antibiotics }\end{array}$ \\
\hline $\begin{array}{l}\text { Webb et } \mathrm{al}^{31} \\
\text { USA }\end{array}$ & $\begin{array}{l}\text { - Quality-improvement } \\
\text { project } \\
\text { - Single tertiary care } \\
\text { facility } \\
\text { - No sample size reported }\end{array}$ & $\begin{array}{l}\text { Evaluate the effectiveness } \\
\text { of antibiotic administration } \\
\text { process on SSI using a } \\
\text { multidisciplinary team } \\
\text { approach }\end{array}$ & $\begin{array}{l}\text { - Interventions included: } \\
\checkmark \text { Development of a list of recommended prophylactic } \\
\text { surgical antibiotics that was adopted as the standard } \\
\text { for the institution } \\
\checkmark \text { Clear antibiotic administration protocol established } \\
\text { (nursing staff to prepare antibiotics, anesthesia staff } \\
\text { to infuse) } \\
\checkmark \text { Electronic quick orders } \\
\checkmark \text { Decreased number of antibiotics for more focused } \\
\text { pharmacy protocols, improving availability of } \\
\text { antibiotics }\end{array}$ \\
\hline $\begin{array}{l}\text { Skoufalos et } \mathrm{al}^{34} \\
\text { USA }\end{array}$ & $\begin{array}{l}\text { - Quality-improvement } \\
\text { project } \\
\text { - No sample size reported }\end{array}$ & $\begin{array}{l}\text { Develop an educational } \\
\text { program to raise awareness of } \\
\text { best practice to reduce SSI by } \\
\text { facilitating collaboration and } \\
\text { teamwork among key } \\
\text { stakeholders }\end{array}$ & $\begin{array}{l}\text { - Patient-centric educational program designed for patients } \\
\text { and stakeholders, such as a web-based tool } \\
\text { - Framework for the toolkit included: } \\
\text { Patient resource section: } \\
\checkmark \text { Preparation for surgery } \\
\checkmark \text { Basic educational material to be used to reinforce } \\
\text { recommended practices with general clinical staff } \\
\text { involved in surgical care } \\
\text { Provider section: } \\
\checkmark \text { Educational materials for surgeons and clinicians with } \\
\text { regard to risk factors and recommended practice } \\
\text { guidelines }\end{array}$ \\
\hline
\end{tabular}




\begin{tabular}{l}
\hline Key findings \\
- Decrease in infection rates for all patients combined \\
$(7.8 \%$ to $4.5 \%, P=0.203)$ \\
- RRR analysis revealed that infection rates were decreased \\
by $43 \%$ overall \\
- Initiative had greater effect on HR group (SSI rate decreased \\
from I $2.9 \%$ to $6.5 \%, P=0.183)$ compared to LR group ( $4.9 \%$ \\
to $2.7 \%, P=0.505)$ \\
- NNT analysis revealed initiative prevented one infection in \\
I 6 HR patients and one in every 30 patients overall up to \\
I year postoperatively
\end{tabular}

I year postoperatively

- Overall SSI rate decreased from $27.3 \%$ (preintervention)

to $18.2 \%$ (postintervention); $P<0.0001$

- Improvement observed in patients with superficial SSI

(16.9\%-13.6\%), organ-space infection $(9.0 \%-4.0 \%)$

- No difference in DVT in the pre- and postintervention groups $(3.2 \%-3.4 \%)$

- Administration of antibiotics in a timely fashion increased from $51 \%$ to $95 \%$

- Percentage of patients given appropriate prophylactic antibiotics increased from $<80 \%$ to $>90 \%$

- Clean wound-infection rates decreased from $\sim 3 \%$ to $\sim 1 \%$

- Multistakeholder collaboration added dimension to discussions and improved the quality of decisions regarding the nature and composition of the toolkit

- SSI toolkit offers the opportunity for stakeholders in a health care-delivery area to adopt and brand compatible tools that are patient-centered

\section{Limitations}

- Small sample size

Quality scores

- Retrospective study using medical records and database

- Single tertiary care facility
- Single site; results not generalizable

- SSI reduction was not followed up after 12 months due to limited resources

- Unable to evaluate contribution of each intervention component due to bundle approach

- Compliance with intervention monitored infrequently

- Confounders not considered
- Wound-infection rates for clean-contaminated wounds not evaluated $36 \%$

- SSI presenting $>30$ days postoperatively not captured

- Problems of inappropriate antibiotics identified, but no description of how they were identified

- Success of studies reported, but no mention of how success measured

- No statistical analysis of SSI rates

- No baseline data to prove intervention was a success

- Site of study and number of cases or participants not reported

- Effect of intervention components not considered

- Methods of data collection/analysis not reported

- Site of project not proposed

- Study end points/outcome not evaluated to determine if SSI had decreased 
Table I (Continued)

\begin{tabular}{|c|c|c|c|}
\hline Study, location & Design and sampling & Aim & Measures/interventions \\
\hline $\begin{array}{l}\text { Travis et } \mathrm{al}^{32} \\
\text { USA }\end{array}$ & $\begin{array}{l}\text { - Quality-improvement } \\
\text { project } \\
\text { - Single hospital site } \\
\text { - No sample size reported }\end{array}$ & $\begin{array}{l}\text { To reduce surgical complications } \\
\text { following CABG surgery } \\
\text { through participation in the } \\
\text { Surgical Care Improvement } \\
\text { Project (SCIP) using a } \\
\text { multidisciplinary focus }\end{array}$ & $\begin{array}{l}\text { Quality-improvement measurements: } \\
\checkmark \text { Administer prophylactic antibiotics within I hour } \\
\text { before surgery } \\
\checkmark \text { Select appropriate prophylactic antibiotics } \\
\checkmark \text { Discontinue prophylactic antibiotics within } 24 \text { hours } \\
\text { at end of surgery } \\
\checkmark \text { Control perioperative serum glucose in major cardiac } \\
\text { surgical patients }\end{array}$ \\
\hline $\begin{array}{l}\text { Roesler et } \mathrm{al}^{23} \\
\text { USA }\end{array}$ & $\begin{array}{l}\text { - Quality-improvement } \\
\text { project } \\
\text { - Single medical center site } \\
\text { - No sample size reported }\end{array}$ & $\begin{array}{l}\text { To evaluate the underlying } \\
\text { problem and eliminate SSI } \\
\text { using a multidisciplinary team } \\
\text { approach }\end{array}$ & $\begin{array}{l}\text { - Interventions to reduce SSI: } \\
\checkmark \text { Mandatory sterile technique in-service programs for } \\
\text { all staff members and physicians } \\
\checkmark \text { Limit the number of personnel in the operating room } \\
\checkmark \text { Maintain positive pressure in each operating room } \\
\checkmark \text { Maintain indoor air temperature and humidity at } \\
\quad \text { comfortable level in health care facilities } \\
\checkmark \text { Maintain clean hospital air-duct system } \\
\checkmark \text { Terminal cleaning in the operating room } \\
\checkmark \text { Use of disinfectants } \\
\checkmark \text { Implemented preoperative wash with chlorhexidine } \\
\text { gluconate wipes for patients }\end{array}$ \\
\hline $\begin{array}{l}\text { Olin } \\
\text { USA }\end{array}$ & $\begin{array}{l}\text { - Quality-improvement } \\
\text { project } \\
\text { - Single hospital site } \\
\text { - No sample size reported }\end{array}$ & $\begin{array}{l}\text { - Increase compliance with } \\
\text { antibiotic measures and patient } \\
\text { care using a multidisciplinary } \\
\text { team approach to reduce SSI }\end{array}$ & $\begin{array}{l}\text { - Interventions included: } \\
\checkmark \text { Adjustment in pharmacy technician delivery routes } \\
\checkmark \text { Administration of antimicrobial in the OR rather than } \\
\text { holding room } \\
\checkmark \text { Choosing antimicrobials according to published } \\
\text { guidelines } \\
\checkmark \text { Discontinuation of antimicrobial prophylaxis within } 24 \\
\text { hours after surgery }\end{array}$ \\
\hline $\begin{array}{l}\text { Berenguer et } \mathrm{al}^{29} \\
\text { USA }\end{array}$ & $\begin{array}{l}\text { - Pretest-posttest study } \\
\text { using retrospective } \\
\text { chart audit } \\
\text { - Data collected from } \\
\text { single hospital site } \\
\text { compared to data } \\
\text { collected from } 244 \\
\text { participating sites } \\
\text { - } \mathrm{n}=197 \text { colorectal cases } \\
\text { in total }\end{array}$ & $\begin{array}{l}\text { Reduce postoperative } \\
\text { complications, such as SSI, } \\
\text { using a multidisciplinary team } \\
\text { approach }\end{array}$ & $\begin{array}{l}\text { - Measures for SSI reduction included: } \\
\checkmark \text { Prophylactic antibiotics received within I hour before } \\
\text { surgical incision } \\
\checkmark \text { Appropriate antibiotic selection } \\
\checkmark \text { Discontinuation of prophylactic antibiotics within } \\
24 \text { hours postsurgically } \\
\checkmark \text { Clippers for hair removal } \\
\checkmark \text { Immediate normothermia postoperatively } \\
\checkmark \text { Normoglycemia for cardiac patients preoperatively }\end{array}$ \\
\hline $\begin{array}{l}\text { Geubbels et } \mathrm{al}^{24} \\
\text { the Netherlands }\end{array}$ & $\begin{array}{l}\text { - Pretest-posttest study } \\
\text { - Five acute care hospitals } \\
\text { - } \mathrm{n}=1,066 \text { patients } \\
\text { preintervention } \\
\text { - } \mathrm{n}=1,269 \text { patients } \\
\text { postintervention }\end{array}$ & $\begin{array}{l}\text { - Demonstrate that } \\
\text { reimplementation of } \\
\text { best-practice interventions } \\
\text { reduces SSI rates }\end{array}$ & $\begin{array}{l}\text { - Interventions: } \\
\text { Hospital A } \\
\checkmark \text { Education program for OR personnel } \\
\checkmark \text { Change of drape and gown material } \\
\text { Hospital B } \\
\checkmark \text { Technical improvement of ventilation system } \\
\checkmark \text { Change setup of instrument table } \\
\checkmark \text { Change antibiotic policy } \\
\checkmark \text { Agreement on who is allowed to open OR door and } \\
\text { for what reasons } \\
\text { Hospital C } \\
\checkmark \text { Surveillance of air quality } \\
\checkmark \text { Transport of patients into the OR on a bed that was } \\
\quad \text { cleaned just before entering } \\
\checkmark \text { Change of drape material } \\
\checkmark \text { Ample rinsing of wound }\end{array}$ \\
\hline
\end{tabular}




Key findings
- Using chart reviews, deep sternal wound-infection rate for
CABG surgeries significantly decreased

CABG surgeries significantly decreased

- No infections from October to May 2008

- Continued education and awareness of the environment is necessary to keep patients safe against SSI

- Best practices and research must be used to continue to combat SSI

- Percentage of compliance with antimicrobial agent administration within I hour of surgery increased from $71 \%$ to $84 \%$

- Choosing appropriate antimicrobial agents had $100 \%$ compliance

- Discontinuation of antimicrobial prophylaxis within 24 hours was increased

First-period results

- Superficial SSI developed in 15 of II 3 colorectal patients

- Rate of hospital SSI was $13.3 \%$ compared to national data rate of $9.7 \%(P=0.04 I)$

Second-period results

- Seven patients (8.3\%) developed superficial SSI

- Rate of institute SSI was $8.3 \%$ compared to national data rate of $10.5 \%(P=0.35 \mathrm{I})$

- Significant rates of SSI have decreased in their institution

Postintervention results

Hospital A

- SSI rate dropped to $2.8 \%$ in the year following the intervention, a difference of $13.9 \%$ from the preintervention rate (95\% Cl 2.3\%-30.1\%)

- Recent evidence shows that SSI rates were reduced to 0 from 2000 to 2002

Hospital B

- SSI rate dropped to $0.9 \%$, a reduction of $5.6 \%$ (95\% Cl I.4\%-9.9\%)

Hospital C

- All improvements were realized

- Postintervention rates were $3.8 \%$ (reduction $2.1 \%, 95 \% \mathrm{Cl}-0.9 \%$ to $5.1 \%$ ) for hip prosthesis, $5.4 \%$ (reduction $10.8 \%, 95 \%$ $\mathrm{Cl}-0.7 \%$ to $22.3 \%$ ) for prosthesis of the femur head, and 0 (reduction 6.1\%, 95\% Cl not calculable) for knee prostheses
Limitations

Quality

scores

- Single site; results not generalizable

$43 \%$

- Retrospective study using medical records and database

- Data analysis used for quality-improvement initiative not discussed

- Single site; results not generalizable

- Implementation methods not described

- Evaluation methods not discussed to assess if initiative implemented was successful

- Data analysis used to detect decrease in SSI or MRSA not discussed in the paper
- Single site; results not generalizable

- Baseline and postintervention results showed increased compliance, but analysis methods not discussed
- Retrospective study using medical records and database

- Rates of superficial SSI were used as an outcome, but no definition of what constitutes a superficial SSI
- Lack of control group

- Hawthorne effect as a possible reason for the observed decrease in rates of SSI 
Table I (Continued)

\begin{tabular}{|c|c|c|c|}
\hline Study, location & Design and sampling & Aim & Measures/interventions \\
\hline & & & $\begin{array}{l}\checkmark \text { Disinfect wound edges after removing adhesive foil } \\
\checkmark \text { Choose bandage requiring less changes } \\
\checkmark \text { Reduce use of drains where possible } \\
\checkmark \text { Agreement on who is allowed to open OR door and } \\
\quad \text { for what reasons } \\
\checkmark \text { All staff to wear surgical masks } \\
\checkmark \text { Abolish wearing of jewelry } \\
\checkmark \text { Use clean closed OR-specific trolley } \\
\checkmark \text { Improve cleaning of OR complex } \\
\checkmark \text { Change packing material of sterile instruments } \\
\checkmark \text { Improve compliance with antibiotic policy } \\
\checkmark \text { Change antibiotic policy } \\
\text { Hospital D } \\
\checkmark \text { Change anticoagulation policy } \\
\text { Hospital E } \\
\checkmark \text { Improve compliance with antibiotic policy }\end{array}$ \\
\hline $\begin{array}{l}\text { Mejia et } \mathrm{al}^{25} \\
\text { USA }\end{array}$ & $\begin{array}{l}\text { - Pretest-posttest study } \\
\text { - Single hospital site } \\
\text { - Sample size not reported }\end{array}$ & $\begin{array}{l}\text { Evaluate the effectiveness of } \\
\text { an interdisciplinary approach } \\
\text { on process-improvement } \\
\text { initiatives to decrease SSI rates } \\
\text { in prosthetic joint replacements }\end{array}$ & $\begin{array}{l}\text { Interventions: } \\
\checkmark \text { Maintaining the sterile environment in the OR, } \\
\text { including reduction of immediate-use steam } \\
\text { sterilization } \\
\checkmark \text { Addressing personnel issues, such as hand asepsis, } \\
\text { vendor presence in the OR, and inexperienced } \\
\text { personnel } \\
\checkmark \text { Assess patient readiness for surgery, including } \\
\checkmark \text { preoperative assessment } \\
\checkmark \text { Resolving system issues, eg, timeliness of reports }\end{array}$ \\
\hline $\begin{array}{l}\text { Dellinger et } \mathrm{al}^{2} \\
\text { USA }\end{array}$ & $\begin{array}{l}\text { - Pretest-posttest study } \\
\text { - } 56 \text { hospitals } \\
\text { - } \mathrm{n}=35,543 \text { surgical cases }\end{array}$ & $\begin{array}{l}\text { - Implement a quality- } \\
\text { improvement approach for } \\
\text { dissemination on a state or } \\
\text { regional level }\end{array}$ & $\begin{array}{l}\text { - Collaborative framework focus: } \\
\checkmark \text { Timeliness of antibiotics } \\
\checkmark \text { Appropriate selection of antibiotics } \\
\checkmark \text { Correct duration of antibiotics } \\
\checkmark \text { Prevent hyperglycemia } \\
\checkmark \text { Maintain normothermia } \\
\checkmark \text { Optimize oxygen tension } \\
\checkmark \text { Avoid shaving surgical site }\end{array}$ \\
\hline $\begin{array}{l}\text { Crolla et } \mathrm{al}^{26} \\
\text { the Netherlands }\end{array}$ & $\begin{array}{l}\text { - Pretest-posttest study } \\
\text { - Single hospital site } \\
\text { - } \mathrm{n}=I, 537 \text { colorectal } \\
\text { procedures }\end{array}$ & $\begin{array}{l}\text { - Implement a care bundle in } \\
\text { colorectal surgery and evaluate } \\
\text { its effect on the SSI rates }\end{array}$ & $\begin{array}{l}\text { - Interventions: } \\
\checkmark \text { Use of razor blade not allowed and replaced by } \\
\text { clippers } \\
\checkmark \text { An explicit and uniform protocol for perioperative } \\
\text { prophylaxis } \\
\checkmark \text { Temperature of patient was measured from the ward } \\
\text { to the OR and back to the ward } \\
\checkmark \text { Isolation blanket administered to patients on ward } \\
\text { before being transported to the ward } \\
\checkmark \text { Determinants of door openings critically assessed and } \\
\text { recommendations made by multidisciplinary team } \\
\checkmark \text { A "safety culture" was promoted for the } \\
\text { implementation of the bundle } \\
\checkmark \text { A newsletter with feedback was provided after each } \\
\text { bundle assessment }\end{array}$ \\
\hline
\end{tabular}




\section{Key findings}

Limitations

Hospital D

- Fewer hematomas and no SSIs were observed

- $\mathrm{SSI}$ rate reduced by $5.4 \%$ ( $95 \% \mathrm{Cl}$ not calculable)

Hospital E

- In the next 18 months, the percentage of patients receiving antibiotic prophylaxis increased to $81 \%$, while SSI rate decreased to $3.6 \%$ (reduction of $11.3 \%, 95 \% \mathrm{Cl} 2.7 \%-19.9 \%$ )

- Combined number of prosthetic joint infections after THA and TKA surgeries decreased from $24(2.5 \%)$ in 2010 to I5 (2.1\%) in 2012

- Reduction in prosthetic joint infection associated with hipprosthesis surgery from 18 in 2010 to nine in 2012 $\left(\chi^{2}=3.057, P=0.04\right)$
- Single site; results not generalizable

- Data for revision procedure may be confounded by data from initial surgeries, as reporting metric did not allow for separation of individuals
- Improvement in median paired performance for each of the process measures ranged from $3 \%$ to $27 \%$

- Overall SSI rate fell $27 \%$ from $2.28 \%$ in the first 3 reporting months to $1.65 \%$ between the first and the last 3 reporting months

- At least ten of 43 (23\%) hospital teams intensified their infection-surveillance efforts during reporting from 3 to 8 months, increasing the likelihood of detecting infections after the first quarter

- Bundle compliance increased from $10 \%$ to $80 \%$ from June 2009 through October 20 II $(P<0.00$ I $)$

- Antibiotic prophylaxis had relatively high compliance during the study period

- Normothermia and hair removal improved during the process, and compliance was high from June 2010 onward

- I,537 colorectal procedures were performed during the study period, and 300 SSIs (195\%) occurred; there were 124 (8.1\%) superficial SSIs and 176 (II.5\%) deep SSIs

- SSI rate was significantly higher in open versus laparoscopic procedures, for surgeons with a lower amount of colorectal procedures, and in patients with a higher ASA score or wound class in nonelective procedures

- Significant reduction of SSI rate observed in 2010 and 20I I, with a $36 \%$ reduction in the last year of the study

- Kaplan-Meier curve for 6-month mortality of patients with and without SSI ( $P<0.0014$ using log-rank test)

- Logistic regression analysis showed that patients with SSIs had a higher likelihood of death within 6 months than those who did not develop an SSI (adjusted odds ratio 2.7I, 95\% Cl I.76-4.18)
- Participating hospitals were free to select the operations to include in the project, and selection of procedures varied widely among hospitals

- Expected infection rates vary widely among procedures, and it was not possible to compare infection rates among hospitals or examine association of specific interventions with changes in infection rates

- Data collected from the pilot surgical populations could not account for the observed decrease in infection rates over time

- Single site; results not generalizable

- Hawthorne effect as a possible reason for the observed decrease in rates of SSI

Abbreviations: OR, operating room; HR, high-risk; LR, low-risk; RRR, relative risk reduction; NNT, number needed to treat; SSI, surgical site infection; THA, total hip arthroplasty; TKA, total knee arthroplasty; MRSA, methicillin-resistant Staphylococcus aureus; DVT, deep-vein thrombosis; Cl, confidence interval; QI, quality-improvement; CABG, coronary artery bypass surgery; ASA, American Society of Anesthesiologists. 


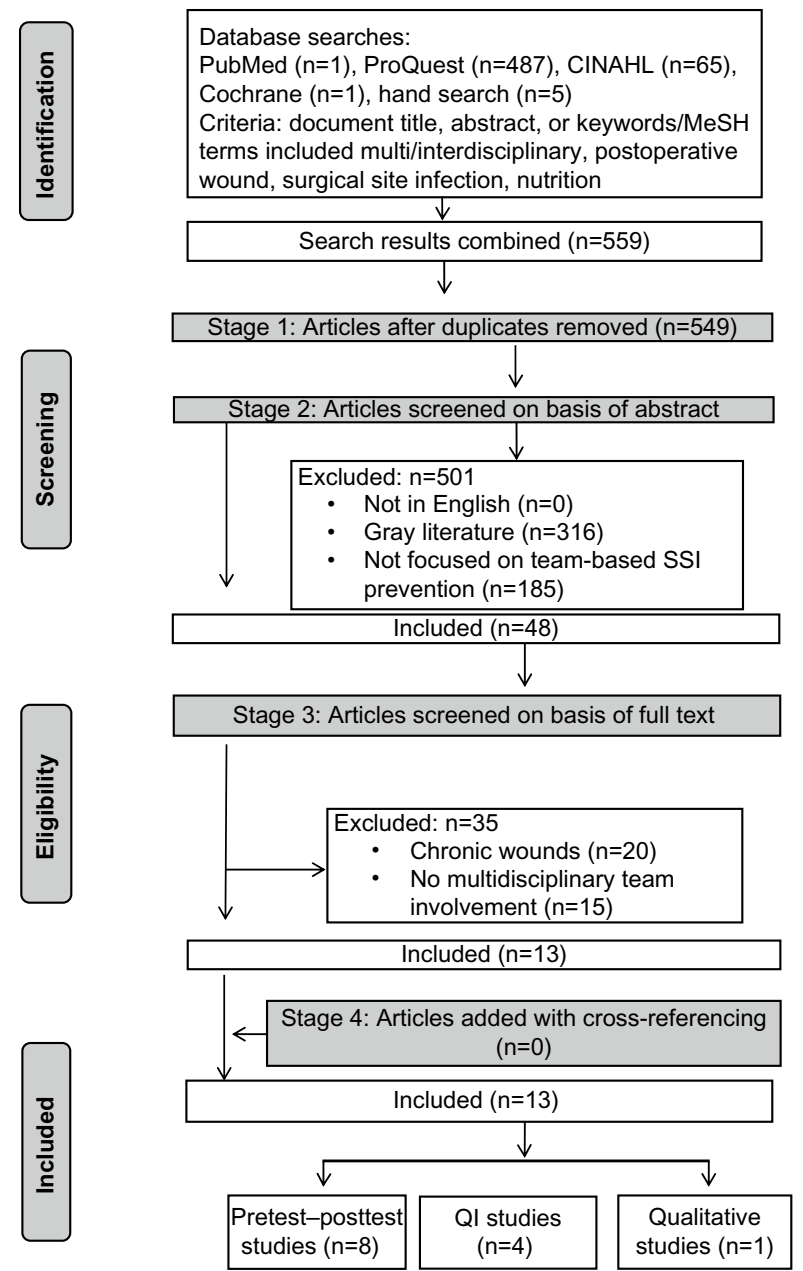

Figure I Flow diagram of papers for inclusion.

Abbreviations: CINAHL, Cumulative Index to Nursing and Allied Health Literature; MeSH, Medical Subject Headings; SSI, surgical site infection; QI, qualityimprovement.

studies $^{2,24-26,31-33}$ described a combination of evidence-based strategies used by multidisciplinary teams to reduce SSI. In nine studies, patient "care bundles" were used, which predominantly focused on three preventive strategies: antibiotic prophylaxis, ${ }^{2,24-26,29,31-33}$ skin antisepsis, ${ }^{23,24,27,28}$ and maintenance of normothermia. ${ }^{26,28}$ Implementation of the care bundles was fleetingly described, and particular tasks were undertaken by individual team members, thus working in parallel rather than interdependently with others in the team. One quality-improvement study specifically focused on the development of a "toolkit" given to patients and staff as part of an SSI-prevention program. ${ }^{34}$ In all studies, the use of preventive strategies promoted shared responsibility among multidisciplinary team members, with each professional discipline being responsible for a particular process or strategy based on their expertise. The interventions implemented by the multidisciplinary teams

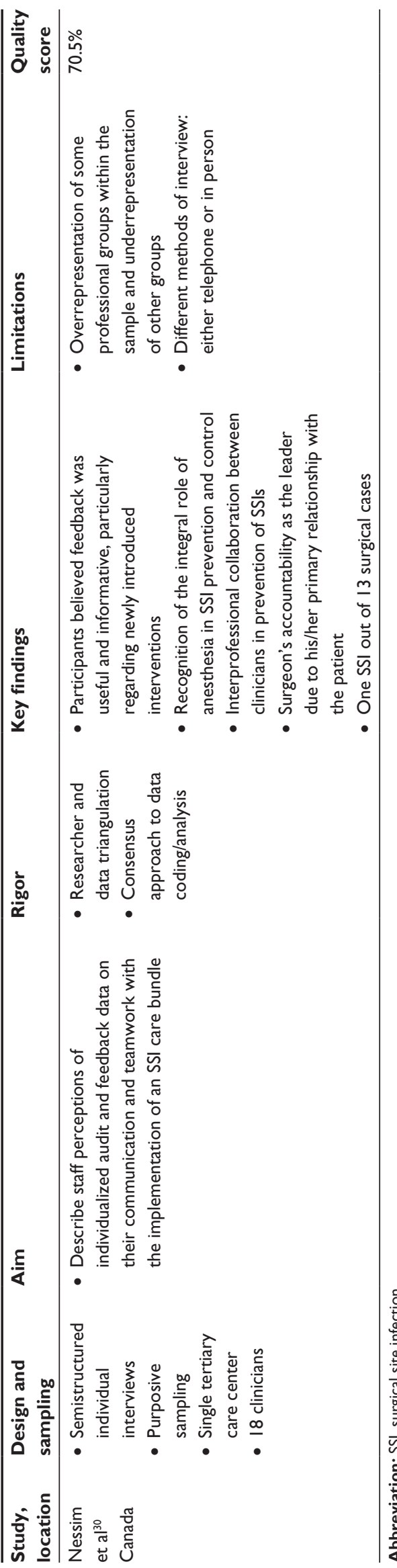


in the reviewed studies were based on best practice, eg, care-bundle components.

Quality assessments of the studies were guided by the SQUIRE guidelines. ${ }^{21}$ Quality scores between the two raters were averaged and calculated as a percentage ranging from $19.5 \%$ to $70.5 \%$. Interrater reliability was calculated, and raters' scores were in good agreement (intraclass correlation coefficient 0.969 , 95\% confidence interval 0.894-0.990; $P<0.001)$.

\section{Discussion}

The findings of this integrative review suggest that the quality of the evidence on multidisciplinary team collaboration in SSI prevention is limited. Most of the studies in this review were quality-improvement activities, and thus may lack the rigor needed to determine how successful team collaborations were in SSI prevention. Further, there was little information on follow-up and sustainability of the multidisciplinary team-based interventions featured in these studies. Preventive interventions necessarily require the concerted efforts of a multidisciplinary team; however, most of the studies reviewed lacked representation of members from disciplines outside medicine and nursing. While this is not surprising in the context of the operating room, a more integrated approach to SSI prevention along the care continuum would include input from other professional groups, such as dietitians, physiotherapists, and occupational therapists. Also, there was little detail offered in relation to how particular interventions actually enhanced team collaborations. Despite this, three themes were identified based on strategies/processes that were commonly used by multidisciplinary teams. These themes are discussed in the following sections.

\section{Using a bundled approach}

All of the included studies described some type of care bundle to maximize the impact of team-based approaches to SSI reduction/prevention. Care bundles are informed by best-practice guidelines, and typically consist of three to five elements of practice that are undertaken as a complete activity in which all specified elements are diligently implemented. ${ }^{35}$ Because they promote standardized care, care bundles reduce the potential for omissions in care that may otherwise result in adverse events. A shift in the thinking that adverse events are inevitable has spawned the rapid adoption of care bundles with a particular focus in clinical practice as a means of reducing or even eliminating adverse events, such as SSI. ${ }^{36}$ The three best-known care bundles are the "ventilator" bundle, ${ }^{37}$ the "sepsis" bundle, ${ }^{38,39}$ and the "central line" bundle. ${ }^{40}$ However, the multifaceted nature of care bundles makes it difficult to establish which component is the "active ingredient", ie, which element may have effected the change in the outcome. While all of the reviewed studies used a multifaceted approach to SSI prevention, a key component of the care bundles was

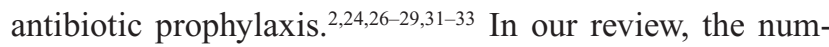
ber of bundle components varied, but most incorporated at least five interventions. However, in those studies ${ }^{2,24-29,31}$ where reductions in SSI rates were reported, it is difficult to determine exactly which component contributed most to these reported reductions. This may be due to the inherent complexity of multifaceted interventions and differences in health care contexts. As most of these reviewed studies were based on quality-improvement methods (rather than randomized controlled trials), causality cannot be established. Notwithstanding, a key focus of process improvement using a care-bundle approach centers on monitoring compliance, ie, the carrying out of bundle components. ${ }^{35}$

Interestingly, only two reviewed studies ${ }^{26,30}$ reported on bundle compliance. Although the primary intent of these care bundles was to prevent SSI, few studies ${ }^{26,30}$ elaborated on which individual components enhanced multidisciplinary collaboration and teamwork. Inconsistencies or a lack of standardization in any aspect of care-bundle delivery where all team members are not adequately trained in its implementation may render the bundle less effective. ${ }^{35}$ Care bundles have the potential to increase team engagement, because team members are able to identify individual and collective contributions to patient care and outcome. ${ }^{35,36}$ Consequently, this process of multidisciplinary collaboration provides an energizing influence within the team, because goals can be explicitly identified and adopted and improvements in patient care are reflected in increased staff morale. Care bundles also reinforce the notion of a shared responsibility within the team, because specific elements are not considered the unique responsibility of designated individuals. ${ }^{30}$ In our reviewed studies, it appeared that the implementation of care-bundle components was circumscribed based on the professional roles of multidisciplinary team members. There was little if any elaboration on the processes individuals used to enhance multidisciplinary collaboration.

\section{Sharing responsibility}

Because there are many factors that increase patients' risk of SSI along the surgical pathway, engaging stakeholders across various hospital departments is crucial. In some of the reviewed studies, effective SSI prevention clearly extended beyond the confines of the operating room. Study 
authors described using strategies targeted to the different phases of the patient journey: from preoperative care through to providing patient-centered education during the early postoperative period..$^{25,27,34}$ The majority of studies described team collaborations that were circumscribed by role: where team members focused on specific tasks, by whom, and in what phase of care in order to mitigate the risk of SSI. The use of such approaches reinforces the notion that each clinician brings with them their particular expertise and is responsible for their respective contributions to patient care.$^{30}$ However, this view is often inconsistent with traditional views, which emphasize that intra- and interprofessional collaboration between clinicians, especially between surgeons and anesthetists, is integral to best practice and ultimately the prevention of SSI. Arguably, collaborations that rely exclusively on an intra- or interprofessional focus may be less inclusive and lead to fragmented patient care. ${ }^{8,41}$ A more holistic approach is achieved when there is a shift in focus from a physician-centric service-delivery model to health care services delivered in a coordinated manner by a suite of health professionals. ${ }^{41}$

In providing holistic health care, there is a growing recognition of the important role that patients themselves play in optimizing care outcomes. Interventions focused on increasing patient participation in their care emphasize the notion of health care being a shared responsibility. ${ }^{42}$ Clearly, the surgical patient is the primary stakeholder who bears the direct consequences of a SSI, and should therefore be given the opportunity to participate in and share responsibility for the prevention of SSI. Notably, only one reviewed study $^{34}$ included patients as stakeholders in SSI prevention, using a web-based education program. While the program was developed from multidisciplinary perspectives, program outcomes were not formally evaluated. Despite this significant limitation, study authors concluded that patient participation in the program increased their awareness of SSI symptoms. ${ }^{34}$ Results of an earlier randomized controlled trial with 588 patients suggested that there was no significant difference $(P=0.399)$ in the proportion of SSI reported/diagnosed in the "educated" patient group versus the "uneducated" group. ${ }^{43}$ Despite insufficient evidence on providing preoperative patient education, a key recommendation arising from the Centers for Disease Control and Prevention and the National Institute for Health and Care Excellence Guidelines $^{3,7}$ is that patients should be given appropriate information about postoperative wound-care principles and the symptoms that may lead to or indicate
SSI. Future research efforts could focus on evaluation of patient-centered interventions intended to increase participation in SSI prevention.

\section{Adhering to best practice}

In all reviewed studies, the SSI-prevention strategies included in care bundles reflected the "big three" best-practice guidelines in SSI prevention (ie, antibiotic administration, normothermia, and skin antisepsis). ${ }^{3,711}$ However, this approach may be limited by the overlooking of other important aspects of SSI prevention. Notably, the limited involvement of allied health professionals, such as dietitians, occupational therapists, and physiotherapists, in multidisciplinary efforts was evident in reviewed studies. Surgical patients are diverse in terms of their ages, risk factors, and comorbidities, etc; therefore, the risk of developing an SSI will differ for each individual patient. Conceivably, some patient cohorts may benefit from the expertise of allied health professionals. For instance, patients with nutritional disorders, such as diabetes and obesity, are at higher risk of SSI, ${ }^{44,45}$ and thus require specialized management pre- and postsurgery. Clearly, there may be marked variability in the impact of nutrition among patients with different stages of disease, or even different treatments (eg, chemotherapy, radiotherapy, advanced disease, serious comorbidities, and emergency surgery). However, patients who are malnourished have compromised immunity ${ }^{46}$ and are at significantly higher risk for developing SSI. ${ }^{45,47}$ The provision of nutrition support to patients presurgery has been shown to be effective in reducing SSI among surgical colorectal cancer patients. ${ }^{48}$

Adding to this complexity, patients who are obese or malnourished are more likely to have poor mobility (due to reduced skeletal muscle mass) and delayed wound healing (due to inadequate tissue perfusion or insufficient nutrients available for tissue repair), ${ }^{46,49,50}$ which in turn may increase hospital length of stay and prolong their risk of exposure to SSI. The role of the multidisciplinary team should extend beyond just adhering to best-practice guidelines; it should take a patient-centered approach to minimizing SSI risk in each individual patient. For example, doctors and pharmacists should be involved in managing blood glucose levels, dietitians should ensure optimal nutrition pre- and postsurgery, and occupational therapists and physiotherapists can work to improve mobility and function postsurgery to facilitate recovery and discharge. Effective communication and understanding of roles between team members is essential, and core to this are nurses, who have the most contact time with patients and thus are in a good position to promote information exchange between patients and clinicians. 
Convening a collection of experts will not necessarily guarantee a better outcome for the patient; in fact, it may have unintended effects and lead to fragmentation of care. ${ }^{8}$ Ideally, a collaborative team-based approach that utilizes the strengths and expertise of members of the health care team is more likely to lead to better patient outcomes. ${ }^{12,13}$ Notably, the role of using a collaborative approach to facilitate coordinated care is increasingly recognized in some of the wound-care standards, ${ }^{10}$ and position statements ${ }^{51}$ recognize and advocate the involvement of allied health professionals as stakeholders in SSI prevention, though it appears that this is yet to be realized in clinical practice. In the context of using a proactive approach to prevention, the limited inclusion of this group as team members warrants exploration. Subsequent research with the purpose of evaluating the contributions of allied health professionals, such as dietitians, would seem both timely and appropriate.

\section{Limitations}

We recognize that this review has some limitations. First, although our search strategies were robust and exhaustive, there is always the possibility that we may have missed some eligible studies. Consequently, this review may not be representative of all relevant work in this field. Second, limitations of the literature itself were reflected in a lack of consistency in the terminology used to describe team collaborations (ie, interdisciplinary/multidisciplinary) across review studies. Therefore, it may be difficult to draw parallels in the ways these teams collaborated, because while teams may share information, they do not necessarily share common understandings, and the group may not generally follow formal processes. ${ }^{41,52}$ Third, studies were assessed using the SQUIRE guidelines, which provide comprehensive descriptors for reporting requirements of quality improvement studies that assess interventions designed to improve the quality and safety of care. However, checklists are subjective, and may reflect individual perceptions of study quality. To address this, two review authors completed quality assessments, with a third reviewer adjudicating where appropriate. Finally, there are methodological limitations of the included review studies: all studies lacked the rigor to determine clearly the impact of multidisciplinary team-based strategies, because they used pre- and posttest designs with significant gaps between time periods, and outcome data relied on secondary data sources using an audit methodology. Notwithstanding these limitations, the rigor of this review has been enhanced through the use of Whittemore and Knafl's framework for integrative reviews. ${ }^{20}$

\section{Conclusion}

The clinical and economic impacts of SSI on patients and health care organizations are profound; therefore, efforts should necessarily focus on prevention. Clearly, preventing SSI is a complex endeavor requiring a multidisciplinary approach that capitalizes on the expertise of various professional groups. Implementation of multidisciplinary strategies in SSI prevention must be consistently applied, responsive to the needs of the individual patient, and supported by the health care organization. This integrative review has identified that using a bundled approach, sharing responsibility, and adhering to best practice are strategies used by multidisciplinary teams in the prevention of SSI. However, to date there appears to be limited involvement of allied health professionals and patients in this endeavor.

\section{Acknowledgment}

BMG, EK, and SR gratefully acknowledge the financial support of the National Health and Medical Research Council (Australia) Centre for Research Excellence in Nursing Interventions for Hospitalised Patients.

\section{Author contributions}

All authors contributed to conception and design, acquisition of data, or analysis and interpretation of data; drafting the article or revising it critically for intellectual content; final approval of the version to be published; and agreement to be accountable for all aspects of the work in ensuring that questions related to the accuracy or integrity of any part of the work are appropriately investigated and resolved.

\section{Disclosure}

The authors report no conflicts of interest in this work.

\section{References}

1. Kassavin DS, Pascarella L, Goldfarb MA. Surgical site infections: incidence and trends at a community teaching hospital. Am J Surg. 2011;201(6):749-753.

2. Dellinger EP, Hausmann SM, Bratzler DW, et al. Hospitals collaborate to decrease surgical site infections. Am J Surg. 2005;190(1):9-15.

3. Mangram A, Horan T, Pearson M, Silver L, Jarvis W. Guideline for prevention of surgical site infection, 1999. Hospital Infection Control Practices Advisory Committee. Infect Control Hosp Epidemiol. 1999;20(4):250-280.

4. Leaper DJ, Van Goor H, Reilly J, et al. Surgical site infection - a European perspective of incidence and economic burden. Int Wound J. 2004;1(4):247-273.

5. Mulligan S, Prentice J, Scott L. WoundsWest Wound Prevalence Survey 2011: State-Wide Overview Report. Perth: Ambulatory Care Services, Department of Health; 2011.

6. Smyth ET, McIlvenny G, Enstone JE, et al. Four Country Healthcare Associated Infection Prevalence Survey 2006: overview of the results. J Hosp Infect. 2008;69(3):230-248. 
7. National Institute for Health and Care Excellence. Surgical Site Infection: Prevention and Treatment of Surgical Site Infection. London: RCOG Press at the Royal College of Obstetricians and Gynaecologists; 2008.

8. World Health Organization. Framework for Action on Interprofessional Education and Collaborative Practice. Geneva: WHO; 2010.

9. Department of Health. SQuIRe 2: CPI Guide to Surgical Site Infection Prevention. Perth: Office of Safety and Quality, WA Government; 2009.

10. Australian Wound Management Association. Standards for Wound Management. 2nd ed. West Leederville, Australia: Cambridge Publishing; 2010.

11. Anderson DJ, Podgorny K, Berríos-Torres SI, et al. Strategies to prevent surgical site infections in acute care hospitals: 2014 update. Infect Control Hosp Epidemiol. 2014;35(6):605-627.

12. Gottrup F. Optimizing wound treatment through health care structuring and professional education. Wound Repair Regen. 2004;12(2): 129-133.

13. Gottrup F, Holstein P, Jørgensen B, Lohmann M, Karlsmar T. A new concept of a multidisciplinary wound healing center and a national expert function of wound healing. Arch Surg. 2001;136(7):765-772.

14. Australian Commission for Safety and Quality in Health Care. National Strategy to Address Health Care Associated Infections: Fourth Report to the Australian Health Ministers Conference. Canberra: ACSQHC; 2003.

15. Webster J, Croger S, Lister C, Doidge M, Terry MJ, Jones I. Use of face masks by non-scrubbed operating room staff: a randomized controlled trial. ANZ J Surg. 2010;80(3):169-173.

16. Royal Australian and New Zealand College of Obstetricians and Gynaecologists. Categorisation of urgency for caesarean section. 2015. Available from: https://www.ranzcog.edu.au/component/docman/ doc_download/948-categorisation-of-urgency-for-caesarean-sectionc-obs-14.html?Itemid=946. Accessed August 10, 2015.

17. Schulz KF, Altman DG, Moher D. CONSORT 2010 statement: updated guidelines for reporting parallel group randomised trials. PLoS Med. 2010;7(3):e1000251.

18. [No authors listed]. Exploring the concept of a team approach to wound care: managing wounds as a team. Journal of Wound Care. 2014;23 Suppl 5b:S1-S38.

19. Newhouse RP, Spring B. Interdisciplinary evidence-based practice: moving from silos to synergy. Nurs Outlook. 2010;58(6):309-317.

20. Whittemore R, Knafl K. The integrative review: updated methodology. J Adv Nurs. 2005;52(5):546-553.

21. Orgrinc G, Mooney S, Estrada C, et al. The SQUIRE (Standards for QUality Improvement Reporting Excellence) guidelines for quality improvement reporting: explanation and elaboration. Qual Saf Health Care. 2008;17 Suppl 1:i13-i32.

22. Polit-O'Hara D. Statistics and Data Analysis for Nursing Research. Boston: Pearson; 2010.

23. Roesler R, Halowell CC, Elias G, Peters J. Chasing zero: our journey to preventing surgical site infection. AORN J. 2010;91(2):224-235.

24. Geubbels EL, Bakker HG, Houtman P, et al. Promoting quality through surveillance of surgical site infections: five prevention success stories. Am J Infect Control. 2004;32(7):424-430.

25. Mejia E, Williams A, Long M. Decreasing prosthetic joint surgical site infections: an interdisciplinary approach. AORN J. 2015;101(2): 213-222.

26. Crolla R, van der Laan L, Veen E, Hendriks Y, van Schendel C, Kluytmans J. Reduction of surgical site infections after implementation of a bundle of care. PLoS One. 2012;7(9):e44599.

27. Ballard MR, Miller NH, Nyquist AC, Elise B, Baulesh DM, Erickson MA. A multidisciplinary approach improves infection rates in pediatric spine surgery. J Pediatr Orthop. 2012;32(3):266-270.

28. Wick EC, Hobson DB, Bennett JL, et al. Implementation of a surgical comprehensive unit-based safety program to reduce surgical site infections. J Am Coll Surg. 2012;215(2):193-200.

29. Berenguer CM, Ochsner MG Jr, Lord SA, Senkowski CK. Improving surgical site infections: using National Surgical Quality Improvement Program data to institute Surgical Care Improvement Project protocols in improving surgical outcomes. J Am Coll Surg. 2010;210(5):737-741.
30. Nessim C, Bensimon CM, Hales B, Laflamme C, Fenech D, Smith A. Surgical site infection prevention: a qualitative analysis of an individualized audit and feedback model. JAm Coll Surg. 2012;215(6): 850-857.

31. Webb AL, Flagg RL, Fink AS. Reducing surgical site infections through a multidisciplinary computerized process for preoperative prophylactic antibiotic administration. Am J Surg. 192(5):663-668.

32. Travis J, Carr JB, Saylor D, et al. Coronary artery bypass graft surgery: surgical site infection prevention. J Healthc Qual. 2009;31(4):16-23.

33. Olin JL. Multidisciplinary approach to optimizing antibiotic prophylaxis of surgical-site infections. Am J Health Syst Pharm. 2006;63(23): 2312-2314

34. Skoufalos A, Clarke JL, Napp M, et al. Improving awareness of best practices to reduce surgical site infection: a multistakeholder approach. Am J Med Qual. 2012;27(4):297-304.

35. Clarkson MD. The role of 'care bundles' in healthcare. Br J Healthc Manag. 2013;19(2):63-68.

36. Humphreys H. Preventing surgical site infection. Where now? J Hosp Infect. 2009;73(4):316-322.

37. Rello J, Chastre J, Cornaglia G, Masterton R. A European care bundle for management of ventilator-associated pneumonia. J Crit Care. 2011;26(1):3-10.

38. Masterton RG. Sepsis care bundles and clinicians. Intensive Care Med. 2009;35(7):1149-1151.

39. Pronovost P, Needham D, Berenholtz S, et al. An intervention to decrease catheter-related bloodstream infections in the ICU. $N$ Engl J Med. 2006;355(26):2725-2732

40. Guerin K, Wagner J, Rains K, Bessesen M. Reduction in central lineassociated bloodstream infections by implementation of a postinsertion care bundle. Am J Infect Control. 2010;38(6):430-433.

41. Chamberlain-Salaun J, Mills J, Usher K. Terminology used to describe health care teams: an integrative review of the literature. $J$ Multidiscip Healthc. 2013;6:65-74.

42. Bucknall T, Chaboyer W, Hutchinson A, et al. Engaging Patients in Communication at Transitions of Care: Final Report. Canberra: Australian Commission on Safety and Quality in Health Care; 2015.

43. Whitby M, McLaws M, Doidge S, Collopy B. Post-discharge surgical site surveillance: does patient education improve reliability of diagnosis? J Hosp Infect. 2007;66(3):237-242.

44. Olsen MA, Nepple JJ, Riew KD, et al. Risk factors for surgical site infection following orthopaedic spinal operations. J Bone Joint Surg Am. 2008;90(1):62-69.

45. Malone DL, Genuit T, Tracy JK, Gannon C, Napolitano LM. Surgical site infections: reanalysis of risk factors. J Surg Res. 2002;103(1):89-95.

46. Stratton RJ, Green CJ, Elia M. Disease-Related Malnutrition: An Evidence-Based Approach to Treatment. Wallingford, UK: CABI; 2003.

47. Schneider SM, Veyres P, Pivot X, et al. Malnutrition is an independent factor associated with nosocomial infections. Br J Nutr. 2004;92(1):105-111.

48. Horie H, Okada M, Kojima M, Nagai H. Favorable effects of preoperative enteral immunonutrition on a surgical site infection in patients with colorectal cancer without malnutrition. Surg Today. 2006;36(12):1063-1068.

49. Vivanti A, Ward N, Haines T. Nutritional status and associations with falls, balance, mobility and functionality during hospital admission. J Nutr Health Aging. 2011;15(5):388-391.

50. Mathison CJ. Skin and wound care challenges in the hospitalized morbidly obese patient. $J$ Wound Ostomy Continence Nurs. 2003;30(2):78-83.

51. European Wound Management Association. Management of wound infection: an integrated approach to managing wound infection: position statement. In: Melling A, Gould F, Gottrup F, editors. Topical Antimicrobials and Surgical Site Infection. London: EWMA; 2006:14-17.

52. Salas E, DiazGranados D, Weaver SJ, King H. Does team training work? Principles for health care. Acad Emerg Med. 2008;15(11): 1002-1009. 


\section{Publish your work in this journal}

The Journal of Multidisciplinary Healthcare is an international, peerreviewed open-access journal that aims to represent and publish research in healthcare areas delivered by practitioners of different disciplines. This includes studies and reviews conducted by multidisciplinary teams as well as research which evaluates the results or conduct of such teams or healthcare processes in general. The journal covers a wide range of areas and welcomes submissions from practitioners at all levels, from all over the world. The manuscript management system is completely online and includes a very quick and fair peer-review system. Visit http://www.dovepress.com/testimonials.php to read real quotes from published authors.

Submit your manuscript here: http://www.dovepress.com/journal-of-multidisciplinary-healthcare-journal 